\title{
Natural course of fat necrosis after breast reconstruction: a 10-year follow-up study
}

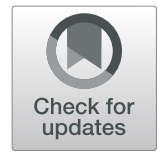

Jeeyeon Lee ${ }^{1}$, Ho Yong Park', Wan Wook Kim¹, Jeong Ju Lee², Hee Jung Keum', Jung Dug Yang³, Jeong Woo Lee ${ }^{4}$, Joon Seok Lee ${ }^{3}$ and Jin Hyang Jung ${ }^{1 *}$

\begin{abstract}
Background: Although fat necrosis is a minor postoperative complication after breast reconstruction, occasionally it mimics to tumor recurrence in patients with breast cancer. Therefore, the surgeon should distinguish between benign fat necrosis and true local recurrence. The authors evaluated the clinical characteristics of fat necrosis after breast reconstruction and investigated the natural course of fat necrosis.

Methods: Between 2007 and 2013, a total of 362 patients underwent breast reconstruction after partial or total mastectomy for breast cancer in Kyungpook National University Hospital. Clinicopathologic characteristics and the occurrence of fat necrosis were assessed during surveillance for 10 years of mean follow-up period.

Results: There were 42 cases (11.6\%) of fat necrosis after breast reconstruction with partial or total mastectomy which were confirmed by needle or excision biopsy. The fat necrosis was resolved after a mean period of 45.9 months (SD, \pm 42.1$)$ and 26 cases (61.9\%) of fat necrosis were almost completely resolved (less than $5 \mathrm{~mm}$ ) during 10-year follow-up period.

Conclusion: Based on the natural course of fat necrosis, the fat necrosis after breast reconstruction can be only monitored, if pathologic confirmation was done. More than half of the cases will be resolved within 2-3 years.
\end{abstract}

Keywords: Breast, Carcinoma, Breast reconstruction, Fat necrosis

\section{Introduction}

Nowadays, the breast surgery for breast cancer should secure not only a oncologic safety but also a better cosmetic outcome [1]. Breast reconstruction after partial or total mastectomy can be achieved with volume displacement, volume replacement techniques or implant-based surgery. The volume displacement technique is performed with the advancement, transposition, or reshaping of the breast parenchyma, whereas the volume replacement technique is performed with adjacent or distant flap surgery [2-6]. As the blood supply of the flap is supported by donor site vessels only, fat necrosis

\footnotetext{
* Correspondence: jjh01@knu.ac.kr

'Department of Surgery, School of Medicine, Kyungpook National University, Kyungpook National University Chilgok Hospital, Hoguk-ro 807, Buk-gu, Daegu 41404, Republic of Korea

Full list of author information is available at the end of the article
}

is more common with the volume replacement technique than with conventional breast-conserving surgery or the volume displacement technique.

Fat necrosis is a benign inflammatory process that is usually associated with various types of traumas including surgery, radiotherapy, biopsy, or infection [7]. Surgical intervention and additional radiotherapy for breast cancer may possibly have some effect on the incidence of fat necrosis $[8,9]$. The incidence of fat necrosis after flap using breast reconstruction has been reported as approximately $4-25 \%$ of patients treated with breastconserving surgery and adjuvant radiotherapy for breast cancer [10-12]. Fat necrosis usually occurs in the focal area that has poor blood supply, such as the peripheral site of the reconstructed flap. Therefore, the incidence of fat necrosis is higher when the volume replacement

C C The Author(s). 2021 Open Access This article is licensed under a Creative Commons Attribution 4.0 International License, which permits use, sharing, adaptation, distribution and reproduction in any medium or format, as long as you give appropriate credit to the original author(s) and the source, provide a link to the Creative Commons licence, and indicate if changes were made. The images or other third party material in this article are included in the article's Creative Commons licence, unless indicated otherwise in a credit line to the material. If material is not included in the article's Creative Commons licence and your intended use is not permitted by statutory regulation or exceeds the permitted use, you will need to obtain permission directly from the copyright holder. To view a copy of this licence, visit http://creativecommons.org/licenses/by/4.0/ The Creative Commons Public Domain Dedication waiver (http://creativecommons.org/publicdomain/zero/1.0/) applies to the data made available in this article, unless otherwise stated in a credit line to the data. 
technique is used instead of the volume displacement technique for breast reconstruction.

Fat necrosis may be suggested with typical imaging features (calcified nodule in mammography and ultrasonography, peripheral site of the reconstructed flap, and poor vascular supply) [13]. However, when the shape of the necrotic nodule shows an irregular or spiculated margin with suspicious microcalcification, it is necessary to distinguish it from tumor recurrence with pathologic confirmation [14].

Although fat necrosis is a minor complication after breast reconstruction, it may cause patient anxiety and inconvenience and sometimes mimic tumor recurrence on the ipsilateral breast. Therefore, it is important for surgeons to understand the natural course of fat necrosis. This study evaluated the clinical characteristics of fat necrosis after breast reconstruction and investigated the natural course of fat necrosis.

\section{Methods}

From 2007 to 2013, a total of 362 patients underwent breast reconstruction after partial or total mastectomy for breast cancer in Kyungpook National University Hospital.

The treatment strategy for breast cancer was determined by multidisciplinary team discussion. Multidisciplinary team discussion involved breast and plastic surgeons, oncologists, radiologists, pathologists, radiation oncologists, and nurses. Neoadjuvant chemotherapy was performed for locally advanced breast cancer (>stage IIIA). Adjuvant treatment, including chemotherapy, radiotherapy, hormone treatment, or target therapy, was performed postoperatively if considered necessary.

Breast cancer tissues were removed completely with a safe margin of $>2 \mathrm{~mm}$, and the surgical margins were pathologically evaluated with frozen and permanent biopsies for the presence of tumor cells. In addition, either sentinel node biopsy or axillary lymph node dissection was performed according to the axillary lymph node status. Volume displacement or replacement techniques were individualized according to the excised breast volume and tumor location, and these techniques included reduction mammoplasty or the use of the lateral thoracodorsal (LTD) flap, intercostal artery perforator (ICAP) flap, thoracodorsal artery perforator (TDAP) flap, thoraco-epigastric (TE) flap, latissimus dorsi (LD) myocutaneous flap, transversus rectus abdominis myocutaneous (TRAM) flap, deep inferior epigastric (DIEP) flap and several other flaps. To reduce the incidence of fat necrosis and maintain vascularity, the plastic surgeons checked the doppler ultrasound on 3-4 points of skin paddle serially from intraoperative, immediate postoperative to postoperative periods. And the intact vascularity of obtained flap was defined when fresh pin-point bleeding was detected in distal margin of flap. After surgery, the plastic surgeons performed a blenching test for $2-3 \mathrm{~s}$ in skin flap and applied the medical leech therapy for 3 days to increase vascularity and flap survival when the blenching test result showed $<1 \mathrm{~s}$ and congestive status of flap.

Adjuvant radiotherapy was delivered to the ipsilateral breast with a radiation dose of $50.4 \mathrm{~Gy}$ in 28 fractions, and a dose of $10 \mathrm{~Gy}$ in 5 fractions was added to the tumor bed. When the closest resection margin was less than $0.1 \mathrm{~cm}$, the patient received additional radiation (14 Gy in 7 fractions).

Clinicopathologic characteristics including age, body mass index, underlying disease, clinical and pathologic tumor size, axillary lymph node status, tumor subtype, neoadjuvant or adjuvant treatment, type of breast reconstruction, weight of the excised specimen, operative time, duration of hospital stay, and occurrence of fat necrosis were assessed. We performed the surveillance for breast cancer per 6 months for first 2 years and per 1 year for next 3 years with mammography, ultrasonography, chest $\mathrm{X}$-ray and laboratory findings including CA15-3, CEA. The oncologic outcomes (loco-regional recurrence, distant metastasis, and death) during the follow-up period were evaluated.

\section{Follow-up of fat necrosis}

When the fat necrosis is suspected in any imaging modalities or patient has clinical symptoms, we performed additional ultrasound and evaluated whether it is benign or suspicious finding. If the suspicious nodule was detected, we performed cytology, needle biopsy or excision case-by-case.

After fat necrosis was pathologically confirmed with cytology, needle biopsy, or excision biopsy, the initial detection time and duration, imaging findings, and size of the necrotic mass during the follow-up period were collected retrospectively. The clinicopathologic and operative variables of patients who had fat necrosis after breast reconstruction with breast reconstruction were also assessed. And the resolution of fat necrosis was defined when the nodule diagnosed as fat necrosis was disappeared in image work-up.

\section{Statistical analysis}

Statistical analysis was performed using SPSS ver. 12.0 (SPSS, Chicago, IL, USA). Categorical variables were analyzed using the $\mathrm{X}^{2}$ test in univariate analysis, and oncologic outcomes were assessed by multivariate analysis using logistic regression to identify factors affecting the locoregional recurrence or distant metastasis of breast cancer. $p$ values of $<0.05$ were considered as statistically significant. 


\section{Results}

The mean age of patients with breast cancer who underwent breast reconstruction after partial or total mastectomy was 45.5 years $(\mathrm{SD}, \pm 7.9)$, and the mean BMI was $23.1 \mathrm{~kg} / \mathrm{m}^{2}$ (SD, \pm 3.0 ). There were 43 patients $(11.8 \%)$ with hypertension and 39 patients $(10.8 \%)$ with diabetes mellitus. The mean clinical and pathologic tumor size was $2.8 \mathrm{~cm}$ and $2.3 \mathrm{~cm}(\mathrm{SD}, \pm 1.6)$, respectively, and 79 patients had axillary lymph nodes metastasis. During the 97.3 months (SD, \pm 23.5 ) of the follow-up period, there were 22 cases (6.1\%) of locoregional recurrence, 15 cases (4.1\%) of distant metastasis, and 9 cases $(2.5 \%)$ of death.

Among a total of 362 cases of breast reconstruction, partial mastectomy with reconstruction was performed in 123 cases (34.0\%), and nipple- or skin-sparing mastectomy with reconstruction was performed in 239 cases (66.0\%). The types of breast reconstruction included reduction mammoplasty or the use of the thoracoepigastric (TE) flap, lateral thoracodorsal (LTD) flap, thoracodorsal artery perforator (TDAP) flap, intercostal artery perforator (ICAP) flap, conventional or extended latissimus dorsi (LD) myocutaneous flap, pedicled or free transversus rectus abdominis myocutaneous (TRAM) flap, deep inferior epigastric (DIEP) flap and several other flaps. The mean weight of the surgical specimen was $231.4 \mathrm{~g}$ (SD, \pm 159.0 ), and the mean operative time was $458.3 \mathrm{~min}(\mathrm{SD}, \pm 116.1)$. The mean hospital stay was 16.1 days $(\mathrm{SD}, \pm 4.5)$. The type of breast surgery or reconstructive surgery, weight of the removed specimen, and operative time were not associated with the occurrence of fat necrosis (Table 1).

Although 42 cases (11.6\%) of fat necrosis were diagnosed during the follow-up period, there was no significant factor associated with the occurrence of fat necrosis after breast reconstruction except for the performance of neoadjuvant chemotherapy $(p=0.044)$. One patient was not received further evaluation after 30 months from surgery. Adjuvant radiotherapy were performed to ten patients $(23.8 \%)$; after breast conserving surgery $(n=9)$ and mastectomy $(n=1)$.

Although there were two cases of locoregional recurrence among them, the recurred site was not breast but the axillary lymph nodes and supraclavicular lymph nodes. In multivariate analysis, it did not show any statistical significance. In addition, the incidence of fat necrosis after breast reconstruction was higher with the pedicled TRAM flap $(n=24,57.2 \%)$. There were 30 cases of microsurgical flaps including free TRAM, DIEP flap and only four cases $(9.5 \%)$ of fat necrosis were identified during follow up period.

The pathologic confirmation of fat necrosis was obtained with fine-needle aspiration cytology $(n=1,2.4 \%)$, needle biopsy $(n=34,81.0 \%)$, and excision biopsy ( $n=7$, $16.7 \%)$. The mean period until the detection of fat necrosis was 21.1 months (SD, \pm 17.2 ), and the mean size of fat necrosis was $2.5 \mathrm{~cm}(\mathrm{SD}, \pm 1.5)$. Most cases were detected through imaging modalities including mammography $(n=13,31 \%)$ and ultrasonography $(n=$ $41,97.6 \%)$, and only one case was detected by breast magnetic resonance (MR) imaging $(\mathrm{n}=1,2.4 \%)$. The combined symptom with fat necrosis were nodular lesion $(n=3)$, pain $(n=6)$ and they were received surgical intervention, if patient wanted (Table 2). Although the mammographic findings of fat necrosis were typically calcification or architectural distortion with calcification (Fig. 1), ultrasonographic findings showed various shapes. Eight cases mimicked tumor recurrence, which required pathologic confirmation, and other cases involved a simple or complex cystic lesion (Fig. 2). And the pathologic results of suspicious nodules mimicking tumor recurrence are described on Table 3.

A total of 26 cases $(61.9 \%)$ of fat necrosis were almost completely resolved during surveillance. The consecutive changes in ultrasonographic findings are shown in Fig. 3, and fat necrosis was resolved after a mean period of 45.9 months (SD, \pm 42.1 ). The mean size of the necrotic nodules was gradually decreased with time, and in most cases, the necrotic nodules were decreased rapidly around 2 years after surgery (Fig. 4).

\section{Discussion}

The rate of breast-conserving surgery among Asian women with breast cancer $(50-60 \%)$ is relatively lower compared with the rate among American or European patients $(70-80 \%)[15,16]$. This difference may be attributed to the small- to moderate-sized breasts and dense breasts of Asian women (reference). Therefore, the incidence of breast reconstruction after partial or total mastectomy may be higher among Asian breast cancer patients.

Fat necrosis can appear as a postoperative complication after breast reconstruction, and the incidence of fat necrosis after flap-based breast reconstruction is approximately $4-25 \%$ of patients treated with breastconserving surgery and adjuvant radiotherapy for breast cancer $[8,9,11,12,17,18]$. In the current study, the incidence of fat necrosis was $11.6 \%$. Even if fat necrosis is only a minor complication, physicians should carefully evaluate their patients because it is necessary to distinguish it from tumor recurrence [19-21]. And although the adjuvant radiotherapy was applied to ten patients (breast conserving surgery $(n=9)$, mastectomy $(n=1)$ ), there was no statistical difference in the incidence of fat necrosis between breast conserving surgery and mastectomy cases. Therefore, the authors suppose that the radiation effect to fat necrosis would be slight.

The identification of fat necrosis can be achieved with clinical examination, mammography, ultrasonography, 
Table 1 Clinicopathologic characteristics of patients who underwent breast reconstruction for breast cancer

\begin{tabular}{|c|c|c|c|}
\hline \multirow[t]{2}{*}{ Variables } & \multirow{2}{*}{$\begin{array}{l}\text { Oncoplastic } \\
\text { surgery } \\
(n=362)\end{array}$} & \multicolumn{2}{|l|}{ Fat necrosis } \\
\hline & & $n=42$ & $p$ value \\
\hline Mean age (years, $\pm S D$ ) & $45.5 \pm 7.9$ & $46.1 \pm 7.4$ & 0.328 \\
\hline Mean body mass index $\left(\mathrm{kg} / \mathrm{m}^{2}, \pm \mathrm{SD}\right)$ & $23.1 \pm 3.0$ & $23.2 \pm 2.1$ & 0.311 \\
\hline Underlying disease (n, \%) & & & 0.402 \\
\hline Hypertension & $43(11.8)$ & $3(7.1)$ & \\
\hline Diabetes mellitus & $39(10.8)$ & $4(9.5)$ & \\
\hline Mean clinical tumor size $(\mathrm{cm}, \pm \mathrm{SD})$ & $2.8 \pm 1.6$ & $2.1 \pm 0.6$ & 0.086 \\
\hline Mean pathologic tumor size $(\mathrm{cm}, \pm \mathrm{SD})$ & $2.3 \pm 1.6$ & $2.7 \pm 1.9$ & 0.619 \\
\hline Estrogen receptor, positive (n, \%) & $189(52.2)$ & $23(54.8)$ & 0.709 \\
\hline Progesterone receptor, positive $(n, \%)$ & $165(45.6)$ & $18(42.9)$ & 0.461 \\
\hline c-erbB2 gene, positive (n, \%) & $69(19.1)$ & $7(16.7)$ & 0.523 \\
\hline Triple-negative breast cancer (n, \%) & $43(11.9)$ & $1(2.4)$ & 0.098 \\
\hline Type of breast surgery (n, \%) & & & 0.269 \\
\hline Partial mastectomy & $123(34.0)$ & $10(23.8)$ & \\
\hline Nipple- or skin-sparing mastectomy & $239(66.0)$ & $32(76.2)$ & \\
\hline Type of reconstructive surgery ( $n, \%)$ & & & 0.222 \\
\hline Reduction mammoplasty & $27(7.5)$ & $2(4.8)$ & \\
\hline Thoraco-epigastric (TE) flap & $4(1.1)$ & - & \\
\hline Lateral thoracodorsal (LTD) flap & $20(5.5)$ & - & \\
\hline Thoracodorsal artery perforator (TDAP) flap & $15(4.1)$ & $2(4.8)$ & \\
\hline Intercostal artery perforator (ICAP) flap & $24(6.6)$ & $2(4.8)$ & \\
\hline Latissimus dorsi (LD) myocutaneous flap & $73(20.2)$ & $3(7.1)$ & \\
\hline Extended LD flap & $102(28.2)$ & $4(9.5)$ & \\
\hline Pedicled Transversus rectus abdominis myocutaneous (TRAM) flap & $59(16.3)$ & $24(57.2)$ & \\
\hline Free TRAM flap & $29(8.0)$ & $4(9.5)$ & \\
\hline Deep inferior epigastric perforators (DIEP) flap & $1(0.3)$ & - & \\
\hline Other flaps & $6(1.7)$ & $1(2.4)$ & \\
\hline Mean weight of specimen $(g, \pm S D)$ & $231.4 \pm 159.0$ & $189.1 \pm 110.4$ & 0.142 \\
\hline Mean operation time (minutes, \pm SD) & $458.3 \pm 116.1$ & $431.3 \pm 106.5$ & 0.610 \\
\hline Mean hospital stay (days, \pm SD) & $16.1 \pm 4.5$ & $16.4 \pm 3.3$ & 0.562 \\
\hline Neoadjuvant chemotherapy (n, \%) & $46(12.7)$ & $2(4.8)$ & 0.044 \\
\hline Adjuvant chemotherapy (n, \%) & $173(47.8)$ & $10(23.8)$ & 0.944 \\
\hline Adjuvant radiotherapy (n, \%) & $105(29.0)$ & $10(23.8)$ & 0.919 \\
\hline Mean follow-up period (months, \pm SD) & $97.3 \pm 23.5$ & $117.0 \pm 26.9$ & 0.184 \\
\hline Locoregional recurrence $(n, \%)$ & $22(6.1)$ & $2(4.8)$ & 0.465 \\
\hline Distant metastasis (n, \%) & $15(4.1)$ & $4(9.5)$ & 0.799 \\
\hline Death $(n, \%)$ & $9(2.5)$ & $2(4.8)$ & 0.625 \\
\hline
\end{tabular}

MRI, or PET/CT [13]. Several studies have reported the imaging findings of fat necrosis using various imaging modalities $[8,17,18,22,23]$. Patient who received breast reconstruction for breast cancer can detect a newly formed nodule, including fat necrosis or tumor recurrence. However, because the Asian female patients commonly have high density of breasts, it would be not easy to distinguish between normal parenchyma and newly formed nodule [24].

The mammographic findings of fat necrosis typically show coarsely calcified nodules with occasional lipidcontaining complex cysts, increased opacity, microcalcification, or architectural distortion. On the other hand, the ultrasonographic findings of fat necrosis are variable 
Table 2 Clinical characteristics associated with fat necrosis after breast reconstruction

\begin{tabular}{|c|c|}
\hline & Fat necrosis $(n=42)$ \\
\hline Mean period until the detection of fat necrosis (months, \pm SD) & $21.1 \pm 17.2$ \\
\hline Mean mass size of fat necrosis at the time of diagnosis ( $\mathrm{cm}, \pm \mathrm{SD}$ ) & $2.5 \pm 1.5$ \\
\hline \multicolumn{2}{|c|}{ Grade $(n, \%)$} \\
\hline \multicolumn{2}{|l|}{1 (Radiologic evidence only) } \\
\hline & $33(78.6)$ \\
\hline \multicolumn{2}{|l|}{2 (Palpable but not visible) } \\
\hline & - \\
\hline \multicolumn{2}{|l|}{3 (Palpable and visible) } \\
\hline & $3(7.1)$ \\
\hline \multicolumn{2}{|l|}{4 (Painful fat necrosis) } \\
\hline & $6(14.3)$ \\
\hline \multicolumn{2}{|l|}{ Imaging modalities ${ }^{\mathrm{a}}(\mathrm{n}, \%)$} \\
\hline Mammography & $13(31.0)$ \\
\hline Ultrasonography & $41(97.6)$ \\
\hline Breast MR imaging & $1(2.4)$ \\
\hline \multicolumn{2}{|l|}{ Pathologic confirmation ( $n, \%)$} \\
\hline Fine-needle aspiration cytology & $1(2.4)$ \\
\hline Needle biopsy & $34(81.0)$ \\
\hline Excision biopsy & $7(16.7)$ \\
\hline \multicolumn{2}{|l|}{ Resolved status (n, \%) } \\
\hline Not resolved & $16(38.1)$ \\
\hline Resolved & $26(61.9)$ \\
\hline Mean period for the complete resolution of fat necrosis (months, $\pm \mathrm{SD}$ ) & $45.9 \pm 42.1$ \\
\hline
\end{tabular}

${ }^{a}$ Method of image modality for detection of fat necrosis could be duplicated

(ranging from a simple or complex cyst to a complex solid nodule). Although solid lesions typically have wellcircumscribed margins, they occasionally have indistinct or spiculated margins mimicking carcinoma [18, 25-28]. Cystic lesions appear as complex cysts with a mural nodule, complex cysts with echogenic bands, or round anechoic lipid cysts $[29,30]$. Breast MR imaging of fat necrosis also shows a wide range of findings. The internal signal characteristics may be identical to those of the adjacent fat or there may be no enhancement after
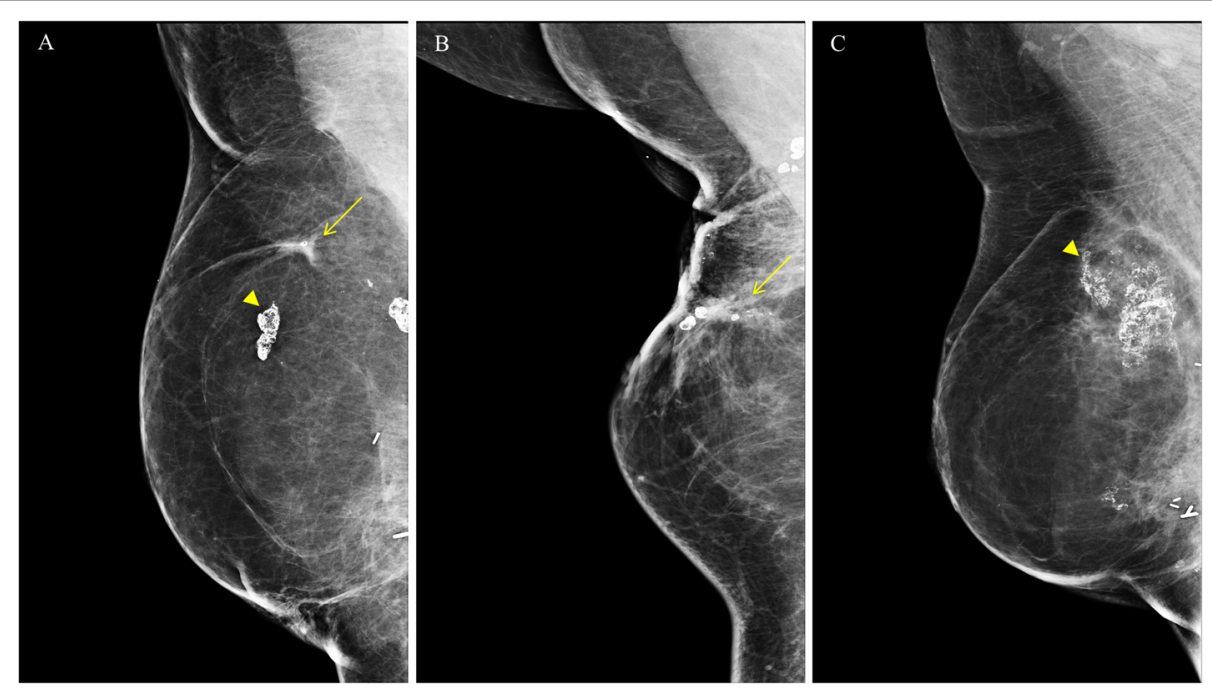

Fig. 1 a-c Mammographic findings of fat necrosis after breast reconstruction. Dystrophic calcification (arrow heads) and architectural distortion (arrows) are common findings in the mammography of fat necrosis 

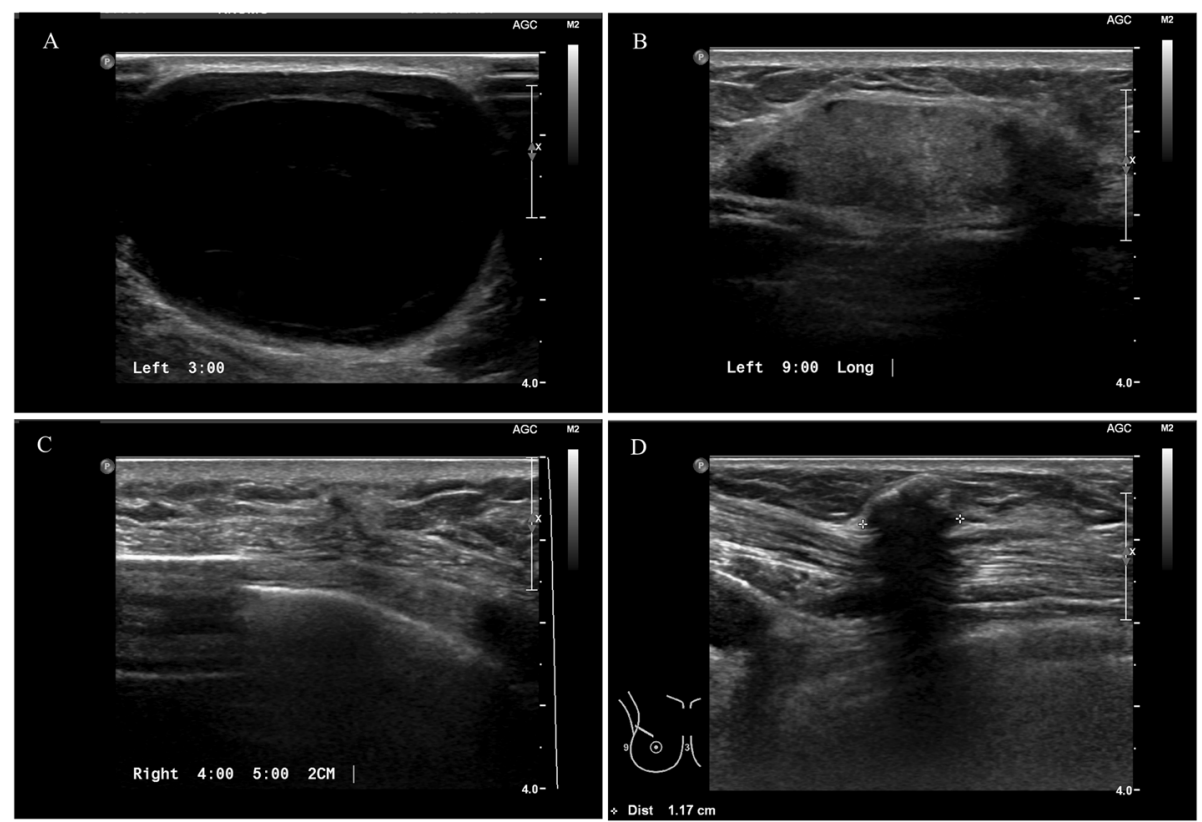

Fig. 2 Ultrasonographic findings of fat necrosis after breast reconstruction. a, b A simple or fat-containing complex cyst is a typical ultrasonographic finding of fat necrosis. $\mathbf{c}$, $\mathbf{d}$ Sometimes the fat necrosis mimics tumor recurrence in ultrasonography as a hypoechoic nodule with irregular margins. In these cases, pathologic confirmation is necessary to distinguish it from tumor recurrence

the administration of contrast material, indicating that the lesion is benign and consistent with fat necrosis. However, contrast enhancement may be present in early periods, complicating efforts to distinguish this entity from recurrent cancer. Enhancement can be focal or diffuse and homogeneous or heterogeneous. Furthermore, enhancement patterns may vary from slow, gradual enhancement to rapid enhancement, and a washout curve may be present $[13,25,29,31]$.

Several surgeons have reported that symptomatic fat necrosis led to a significantly worse cosmetic outcome and that asymptomatic fat necrosis did not demonstrate evidence of cosmetic abnormality [8, 9, 32, 33].

Table 3 Management of suspicious nodules after breast cancer surgery which is mimicking the tumor recurrence

\begin{tabular}{ll}
\hline & $\mathbf{n}(\%)$ \\
\hline $\begin{array}{l}\text { Cuspicious nodule mimicking the tumor recurrence } \\
\text { Needle biopsy }\end{array}$ & $8(19.0)$ \\
Excision & $6(14.3)$ \\
Pathologic results of biopsy & $2(4.8)$ \\
Chronic inflammation with fat necrosis & \\
Stromal fibrosis with fat necrosis & $3(7.3)$ \\
Fat necrosis with calcification & $3(7.3)$ \\
Only fat necrosis & $1(2.4)$ \\
\hline
\end{tabular}

However, they did not observe a significant deterioration in cosmetic outcome for patients who developed fat necrosis. Most cases of fat necrosis may be resolved without intervention or do not show any changes [17, 34]. In this study, more than $60 \%$ of fat necrosis cases were spontaneously resolved without any procedures. Around 2 years after the occurrence of fat necrosis, the size of the necrotic nodules was decreased by half and remained constant without significant changes.

According to the literature, the timing of fat necrosis development after breast reconstruction varies widely. Wazer et al. reported the development of fat necrosis as early as 7.5 months [35]. Chen et al. reported fat necrosis at a median time of 66 months [36]. In this study, the mean period until the detection of fat necrosis was 21.1 months from surgery with clinical examination or imaging modalities including mammography, ultrasonography, or breast MR imaging. In addition, the location of fat necrosis after breast reconstruction has been reported to be different based on the surgical techniques used. As fat necrosis is affected by poor blood supply from the breast or flap tissues, the location could be identified with various techniques.

Several risk factors associated with the occurrence of fat necrosis after surgery have been proposed, which include neoadjuvant chemotherapy, adjuvant radiotherapy, high BMI, and uncontrolled underlying disease [37-40]. However, there was no significant factor associated with fat necrosis in our study. The performance of 

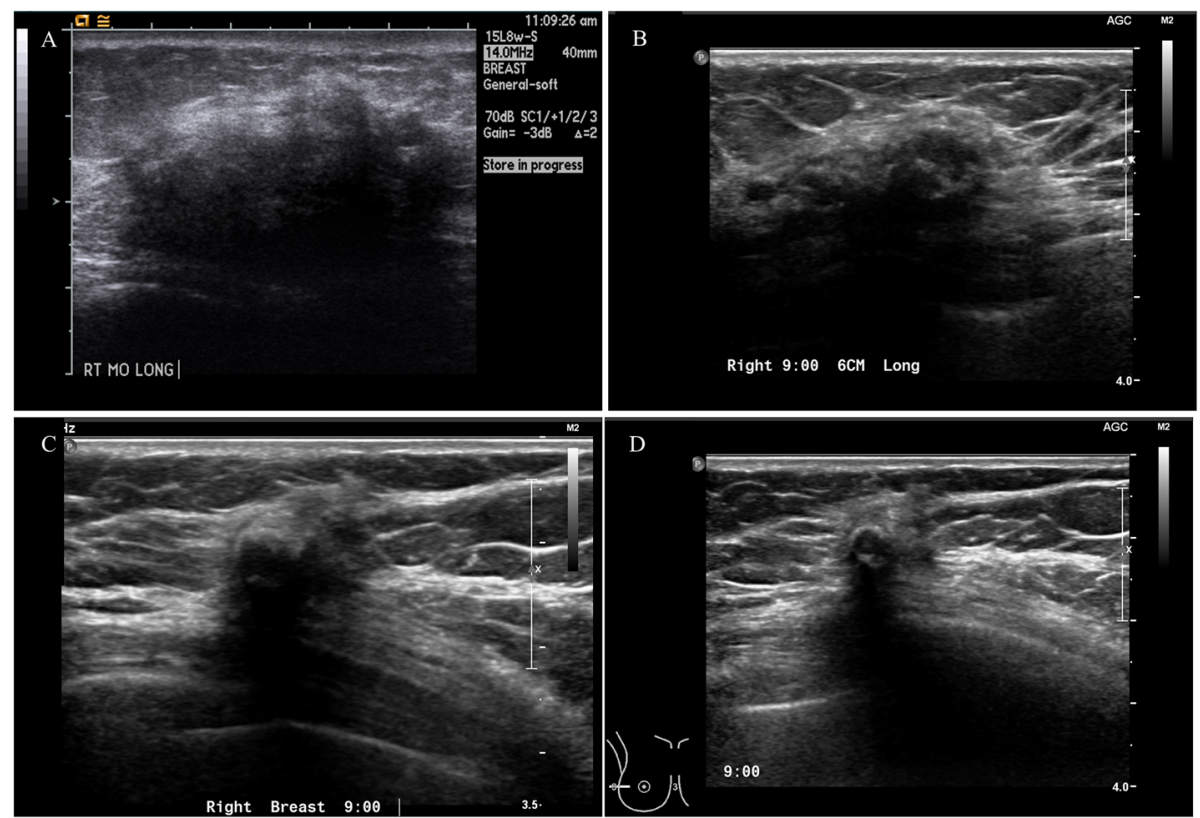

Fig. 3 Consecutive changes in fat necrosis after breast reconstruction in ultrasonography. a Initially, fat necrosis was detected after 6 months from surgery as a mass of around $4 \mathrm{~cm}$ with an indistinct margin in the mid-outer portion of the right breast. Needle biopsy was performed, and fat necrosis was confirmed pathologically. b After 1 year from the detection of fat necrosis, the volume of the necrotic mass was decreased. And calcification appeared at the center of the fat necrosis area (arrowhead). c After 2 year from the occurrence of fat necrosis, the mass was shrunk further. $\mathbf{d}$ Although the mass became much smaller over time, calcification (arrowhead) remained at the fat necrosis area

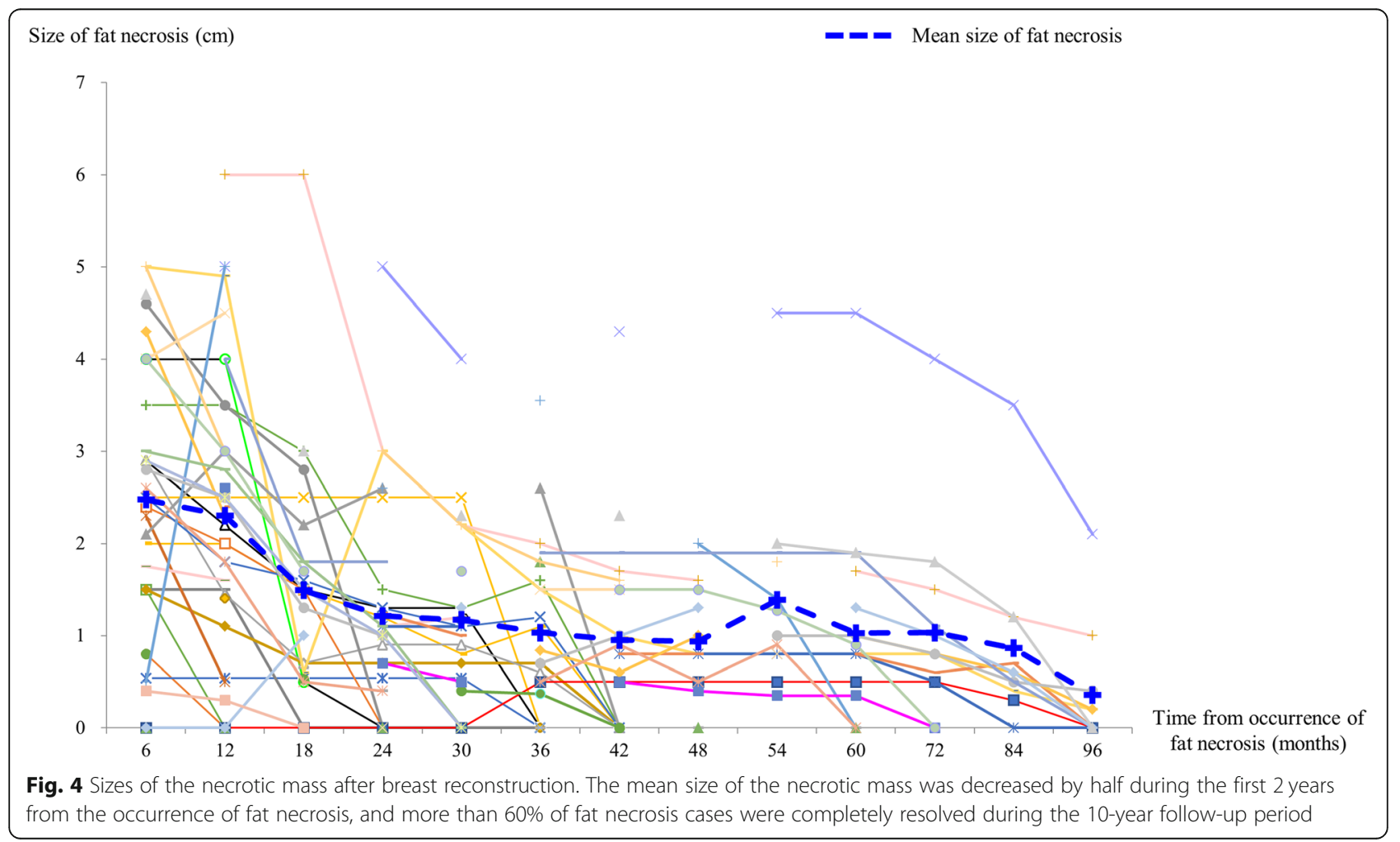


neoadjuvant chemotherapy was only associated with fat necrosis in univariate analysis but not multivariate analysis.

In our study, the radiologist who is an expert in breast with more than 15 years of experiences performed and analyzed about the fat necrosis. If she had been a less experienced radiologist, there would be more cases which requires the pathologic confirmation. In addition, the fat necrosis after breast reconstruction could not be observed as prospective study and this is another limitation in our study.

If the imaging findings of fat necrosis reveal a suspicious lesion, pathologic confirmation should be obtained to rule out tumor recurrence. However, as fat necrosis may resolve independently within 2-3 years, the management of fat necrosis can be performed only through observation if fat necrosis is highly probable or pathologically confirmed. An understanding of the natural course of fat necrosis would be helpful for the management of fat necrosis.

In conclusion, fat necrosis after breast reconstruction for breast cancer is relatively common; nevertheless, it is only a benign complication. Sometimes, it can mimic tumor recurrence, and pathologic confirmation is needed. However, if fat necrosis after breast reconstruction is confirmed, it can only be observed based on its natural course and more than half of the cases will be resolved within 2-3 years.

\section{Supplementary Information}

The online version contains supplementary material available at https://doi. org/10.1186/s12885-021-07881-x.

\section{Additional file 1.}

\section{Abbreviations}

TE: Thoraco-epigastric; LTD: Lateral thoracodorsal; TDAP: Thoracodorsal artery perforator; ICAP: Intercostal artery perforator; LD: Latissimus dorsi; TRAM: Transversus rectus abdominis myocutaneous; DIEP: Deep inferior epigastric; MR: Magnetic resonance

\section{Acknowledgements}

Not Applicable.

\section{Authors' contributions}

$J \mathrm{~L}$ and $\mathrm{JHJ}$ contributed to the study design and manuscript writing. HYP WWK, J JL conducted the literature research and clinical practice. And HJK JDY, JWL and JSL also contributed to the data acquisition and analysis. JHJ reviewed the manuscript and made revisions. All authors read and approved the final manuscript.

\section{Funding}

This work was supported by the National Research Foundation of Korea (NRF) grant funded by the Korea government (2014R1A5A2009242, 2019R1F1A1063853) and by a grant from the National R\&D Program for Cancer Control, Ministry of Health and Welfare, Republic of Korea (1420040). And this research was supported by a grant of the Korea Health Technology R\&D Project through the Korea Health Industry Development Institute (KHID I), funded by the Ministry of Health \& Welfare, Republic of Korea (HI17C1142). This work was supported by the National Research Foundation of Korea
(NRF) grant funded by the Korea government (MSIT) (NRF2019R1A2C1006264). This work was supported by the National Research Foundation of Korea (NRF) grant funded by the Korea government (2017M3A9G8083382)

\section{Availability of data and materials}

The datasets generated and/or analyzed during the current study are not publicly available due to the data is in company's possession. But, they are available from the corresponding author on reasonable request.

\section{Ethics approval and consent to participate}

Informed consent was obtained from all patients and the protocol used in this study was approved by the Institutional Review Board (IRB) Committee of Kyungpook National University Chilgok Hospital, Daegu, Republic of Korea (2015-05-205). And the specific inclusion and exclusion criteria were defined in the approved IRB protocol. The informed consents were obtained by written documents from all patients.

\section{Consent for publication}

Not applicable.

\section{Competing interests}

The authors declare that they have no competing interests.

\section{Author details}

${ }^{1}$ Department of Surgery, School of Medicine, Kyungpook National University, Kyungpook National University Chilgok Hospital, Hoguk-ro 807, Buk-gu, Daegu 41404, Republic of Korea. ${ }^{2}$ Department of Surgery, Boonhongbitzro Hospital, Daegu, Republic of Korea. ${ }^{3}$ Department of Plastic and Reconstructive Surgery, School of Medicine, Kyungpook National University, Kyungpook National University Chilgok Hospital, Daegu, Republic of Korea. ${ }^{4}$ Department of Plastic and Reconstructive Surgery, School of Medicine, Kyungpook National University, Kyungpook National University Hospital, Daegu, Republic of Korea.

Received: 21 June 2020 Accepted: 4 February 2021

Published online: 16 February 2021

\section{References}

1. WP. A. Surgery of the breast: principles and art. edition. S, editor. Philadelphia: Lippincott Williams \& Wilkins; 2006

2. van Paridon MW, Kamali P, Paul MA, Wu W, Ibrahim AMS, Kansal KJ, et al. Oncoplastic breast surgery: achieving oncological and aesthetic outcomes. J Surg Oncol. 2017;116(2):195-202.

3. Hamdi M. Oncoplastic and reconstructive surgery of the breast. Breast (Edinburgh, Scotland). 2013;22(Suppl 2):S100-5.

4. Losken A, Hamdi M. Partial breast reconstruction: current perspectives. Plast Reconstr Surg. 2009;124(3):722-36.

5. Hamdi M, Van Landuyt K, Hijjawi JB, Roche N, Blondeel P, Monstrey S. Surgical technique in pedicled thoracodorsal artery perforator flaps: a clinical experience with 99 patients. Plast Reconstr Surg. 2008;121(5):163241.

6. Hamdi M, Spano A, Van Landuyt K, D'Herde K, Blondeel P, Monstrey S. The lateral intercostal artery perforators: anatomical study and clinical application in breast surgery. Plast Reconstr Surg. 2008;121(2):389-96.

7. Tan PH, Lai LM, Carrington EV, Opaluwa AS, Ravikumar KH, Chetty N, et al. Fat necrosis of the breast--a review, Breast (Edinburgh, Scotland). 2006;15(3): 313-8.

8. Lovey K, Fodor J, Major T, Szabo E, Orosz Z, Sulyok Z, et al. Fat necrosis after partial-breast irradiation with brachytherapy or electron irradiation versus standard whole-breast radiotherapy--4-year results of a randomized trial. Int J Radiat Oncol Biol Phys. 2007;69(3):724-31.

9. Ott OJ, Schulz-Wendtland R, Uter W, Pfahlberg A, Beckmann MW, Sauer R, et al. Fat necrosis after conserving surgery and interstitial brachytherapy and/or external-beam irradiation in women with breast cancer. Strahlentherapie und Onkologie : Organ der Deutschen Rontgengesellschaft [et al]. 2005:181(10):638-44.

10. Trombetta M, Valakh V, Julian TB, Werts ED, Parda D. Mammary fat necrosis following radiotherapy in the conservative management of localized breast cancer: does it matter? Radiotherapy Oncol. 2010;97(1):92-4. 
11. Nakada H, Inoue M, Furuya K, Watanabe H, Ikegame K, Nakayama Y, et al. Fat necrosis after breast-conserving oncoplastic surgery. Breast cancer (Tokyo, Japan). 2019;26(1):125-30.

12. Lin JY, Song P, Pu LLQ. Management of Fat Necrosis after Autologous Fat Transplantation for Breast Augmentation. Plastic Reconstructive Surg. 2018; 142(5):665e-73e.

13. Kerridge WD, Kryvenko ON, Thompson A, Shah BA. Fat necrosis of the breast: A pictorial review of the mammographic, ultrasound, $C T$, and MRI findings with Histopathologic correlation. Radiology Res Practice. 2015;2015: 613139.

14. Tayyab SJ, Adrada BE, Rauch GM, Yang WT. A pictorial review: multimodality imaging of benign and suspicious features of fat necrosis in the breast. $\mathrm{Br} J$ Radiol. 2018;91(1092):20180213.

15. Kroll SS. Fat necrosis in free transverse rectus abdominis myocutaneous and deep inferior epigastric perforator flaps. Plast Reconstr Surg. 2000;106(3): 576-83.

16. Nahabedian MY, Momen B, Galdino G, Manson PN. Breast reconstruction with the free TRAM or DIEP flap: patient selection, choice of flap, and outcome. Plast Reconstr Surg. 2002;110(2):466-75 discussion 76-7.

17. Hogge JP, Robinson RE, Magnant CM, Zuurbier RA. The mammographic spectrum of fat necrosis of the breast. Radiographics. 1995:15(6):1347-56.

18. Taboada JL, Stephens TW, Krishnamurthy S, Brandt KR, Whitman GJ. The many faces of fat necrosis in the breast. AJR Am J Roentgenol. 2009;192(3): 815-25

19. Egro FM, Pinell-White $X$, Hart AM, Losken A. The use of reduction mammaplasty with breast conservation therapy: an analysis of timing and outcomes. Plastic Reconstructive Surg. 2015;135(6):963e-71e.

20. Mele S, Wright D, Paramanathan N, Laws S, Peiris L, Rainsbury R. Long-term effect of oncoplastic breast-conserving surgery using latissimus dorsi miniflaps on mammographic surveillance and the detection of local recurrence. J Plastic Reconstructive Aesthetic Surg. 2017;70(9):1203-9.

21. Dolan R, Patel M, Weiler-Mithoff E, Mansell J, Stallard S, Doughty JC, et al. Imaging Results Following Oncoplastic and Standard Breast Conserving Surgery. Breast Care (Basel, Switzerland). 2015;10(5):325-9.

22. Solomon B, Orel S, Reynolds C, Schnall M. Delayed development of enhancement in fat necrosis after breast conservation therapy: a potential pitfall of MR imaging of the breast. AJR Am J Roentgenol. 1998;170(4):966-8

23. Ganau S, Tortajada L, Escribano F, Andreu X, Sentis M. The great mimicker: fat necrosis of the breast--magnetic resonance mammography approach. Curr Probl Diagn Radiol. 2009;38(4):189-97.

24. Amitai Y, Golan O, Barnea Y, Klausner J, Menes TS. Follow-up of patients undergoing oncoplastic surgery - more palpable masses and benign biopsies. Breast Disease. 2018;37(3):115-21.

25. Hassan HHM, El Abd AM, Abdel Bary A, Naguib NNN. Fat necrosis of the breast: magnetic resonance imaging characteristics and pathologic correlation. Acad Radiol. 2018;25(8):985-92.

26. Dorner J, Malter W, Markiefka B, Krug KB. Value of multiparametric magnetic resonance imaging of the breast for the differentiation of fat necrosis and tumor recurrence after breast-conserving surgery: A case report. RoFo Fortschritte auf dem Gebiete der Rontgenstrahlen und der Nuklearmedizin. 2018;190(2):175-7.

27. Gigli S, Amabile MI, F DIP, A DEL, Gulia C, Manganaro L, et al. Lipofilling outcomes mimicking breast Cancer recurrence: case report and update of the literature. Anticancer Res. 2017;37(10):5395-8.

28. Piper M, Peled AW, Sbitany H, Foster RD, Esserman LJ, Price ER. Comparison of mammographic findings following Oncoplastic mammoplasty and lumpectomy without reconstruction. Ann Surg Oncol. 2016;23(1):65-71.

29. Atasoy MM, Oren NC, llica AT, Guvenc I, Gunal A, Mossa-Basha M. Sonography of fat necrosis of the breast: correlation with mammography and MR imaging. J Clinical Ultrasound. 2013;41(7):415-23.

30. Bilgen IG, Ustun EE, Memis A. Fat necrosis of the breast: clinical, mammographic and sonographic features. Eur J Radiol. 2001;39(2):92-9.

31. Whitehouse $\mathrm{GH}$, Moore NR. MR imaging of the breast after surgery for breast cancer. Magn Reson Imaging Clin N Am. 1994;2(4):591-603.

32. Polgar C, Major T, Fodor J, Nemeth G, Orosz Z, Sulyok Z, et al. High-doserate brachytherapy alone versus whole breast radiotherapy with or without tumor bed boost after breast-conserving surgery: seven-year results of a comparative study. Int J Radiat Oncol Biol Phys. 2004;60(4):1173-81.

33. Chen PY, Vicini FA, Benitez P, Kestin LL, Wallace M, Mitchell C, et al. Longterm cosmetic results and toxicity after accelerated partial-breast irradiation: a method of radiation delivery by interstitial brachytherapy for the treatment of early-stage breast carcinoma. Cancer. 2006;106(5):991-9.

34. Stigers KB, King JG, Davey DD, Stelling CB. Abnormalities of the breast caused by biopsy: spectrum of mammographic findings. AJR Am J Roentgenol. 1991;156(2):287-91.

35. Wazer DE, Lowther D, Boyle T, Ulin K, Neuschatz A, Ruthazer R, et al. Clinically evident fat necrosis in women treated with high-dose-rate brachytherapy alone for early-stage breast cancer. Int J Radiat Oncol Biol Phys. 2001;50(1):107-11.

36. DiPiro PJ, Meyer JE, Frenna TH, Denison CM. Seat belt injuries of the breast: findings on mammography and sonography. AJR Am J Roentgenol. 1995; 164(2):317-20

37. Dal Cin A, Knight C, Whelan KF, Farrokhyar F. Bilateral reduction mammoplasty following breast cancer: A case-control study. Canadian J Plastic Surg = Journal canadien de chirurgie plastique. 2012;20(1):e6-9.

38. Parrett BM, Schook C, Morris D. Breast reduction in the irradiated breast: evidence for the role of breast reduction at the time of lumpectomy. Breast J. 2010;16(5):498-502.

39. Zhang $M X$, Chen $C Y$, Fang $Q Q, X u J H$, Wang XF, Shi BH, et al. Risk factors for complications after reduction mammoplasty: A meta-analysis. PLoS One. 2016;11(12):e0167746.

40. Lewin R, Goransson M, Elander A, Thorarinsson A, Lundberg J, Liden M. Risk factors for complications after breast reduction surgery. J Plastic Surg Hand Surg. 2014;48(1):10-4.

\section{Publisher's Note}

Springer Nature remains neutral with regard to jurisdictional claims in published maps and institutional affiliations.

Ready to submit your research? Choose BMC and benefit from:

- fast, convenient online submission

- thorough peer review by experienced researchers in your field

- rapid publication on acceptance

- support for research data, including large and complex data types

- gold Open Access which fosters wider collaboration and increased citations

- maximum visibility for your research: over $100 \mathrm{M}$ website views per year

At $\mathrm{BMC}$, research is always in progress.

Learn more biomedcentral.com/submissions 